\title{
人工ナノ粒子導入による $\mathrm{BaFe}_{2}\left(\mathrm{As}_{1-x} \mathrm{P}_{x}\right)_{2}$ 薄膜の磁場中超伝導特性向上
}

三浦 正志 ${ }^{* 1}$

\section{Enhanced In-field Properties in $\mathrm{BaFe}_{2}\left(\mathrm{As}_{1-x} \mathrm{P}_{x}\right)_{2}$ Thin Films with $\mathrm{BaZrO}_{3}$ Nanoparticles}

\author{
Masashi MIURA*1
}

Synopsis: This paper reviews our study on in-field superconducting properties and thermally activated vortex motion (creep) in $\mathrm{BaFe}_{2}\left(\mathrm{As}_{1-x} \mathrm{P}_{x}\right)_{2}\left(\mathrm{Ba122: \textrm {P } )}\right.$ thin films with $\mathrm{BaZrO}_{3}$ nanoparticles fabricated on a $\mathrm{MgO}$ single crystal using pulsed laser deposition (PLD). We demonstrated that introducing controlled uniformly dispersed $\mathrm{BaZrO}_{3}$ nanoparticles into $\mathrm{Ba122:P}$ films significantly improves its in-field superconducting properties without degrading crystallinity, critical temperature and self-field critical current density $\left(J_{\mathrm{c}}\right)$. The nanoparticles doped Ba122:P films show an increase in $J_{\mathrm{c}}$ at all magnetic-field orientations and significantly reduced vortex creep, indicating that nanocomposite films could be a promising candidate for in-field applications.

Keywords: iron-based film, flux pinning, critical current density, nanoparticles, pulsed laser deposition (PLD)

(Some figures in this article may appear in colour only in the electronic version)

\section{1. はじめに}

東工大の細野秀雄教授のグループによって 2006 年に $\mathrm{LaFePO}{ }^{1)} 、 2008$ 年に $\mathrm{LaFeAsO}{ }^{2)}$ など鉄系超伝導体が発見 され、基礎物理だけでなく応用の面でも注目を浴び、多く の研究者が研究を行っている。鉄系超伝導材料の中でも $\mathrm{BaFe}_{2} \mathrm{As}_{2}(\mathrm{Ba} 122)$ は、異方性が小さく、比較的臨界温度 $\left(T_{\mathrm{c}}\right)$ が高く 3$)$ 、パルスレーザー蒸着法 (PLD) や分子線エ ピタキシー (MBE) 法などの気相法を用いて安定的に作製 できることが確認されている 4-7)。エネルギー高効率利用 に貢献することが期待されている超伝導磁石を用いた風力 用発電機や電力貯蔵装置 (SMES) などの磁場応用に向け て、超伝導材料の線材化が必要となる。高温超伝導体であ る $\mathrm{REBa}_{2} \mathrm{Cu}_{3} \mathrm{O}_{y}(\mathrm{RE} 123)$ などでは、クーパー対の対称性が $\mathrm{d}$ 波であるため、結晶粒界の角度が 5 度以上で臨界電流密 度 $\left(J_{\mathrm{c}}\right)$ が急激に低下寸ることが知られている ${ }^{8)}$ 。その ため、パウダー・イン・チューブ (PIT) 法などを用いて RE123 材料の線材化が難しいため、金属基板上にバッ ファー層、中間層、超伝導層を重ねたコート線材の開発が 主になっている 9-11)。一方、Ba122 などの鉄系超伝導材料 は、クーパー対の対称性が $\mathrm{s}$ 波的と考えられ、結晶粒界に

Received August 14, 2017

${ }^{* 1}$ 成蹊大学大学院 理工学研究科

干180-8633 東京都武蔵野市吉祥寺北町 3-3-1

Graduate School of Science and Technology, Seikei University,

3-3-1 Kichijoji-Kitamachi, Musashino, Tokyo 180-8633, Japan

E-mail: masashi-m@st.seikei.ac.jp

DOI: $10.2221 /$ jcsj.52.448
対する $J_{\mathrm{c}}$ の低下が RE123 に比べて小さいことが報告され ている ${ }^{12)}$ 。それ故、PIT 法による線材化の研究が盛んに行 われている 13-16)。また、PLD 法や MBE 法などの薄膜化 技術により基板に対して 2 軸配向したエピタキシャル薄膜 の実現により PIT 法 Ba122 線材に比べて $J_{\mathrm{c}}$ 特性が高いこ とが報告されている 4-7)。最近では、RE123 線材同様に金 属基板上に Ba122 薄膜を蒸着したコート線材でも特性が 高いことが報告されている ${ }^{17,18)}$ 。

磁場応用に向けては、磁場中 $J_{\mathrm{c}}$ 特性を向上させること が線材化と同じくらい必要とされている。そのためには、 ローレンツカによる量子化磁束の運動を磁束ピンニング点 導入により抑制する必要がある。RE123 線材において は、PLD 法、有機金属気相堆積法 (MOCVD)、金属有機 化合物分解法 (MOD) などの手法を用いて磁束のサイズと 同程度のナノメートルサイズの非超電導相を導入する研究 が盛んに行われている 19-26)。一方、Ba122 系鉄系超伝導薄 膜における人工欠陷導入による磁場中 $J_{\mathrm{c}}$ 向上の研究は、 米国 Wisconsin 大によって $\mathrm{Ba}\left(\mathrm{Fe}_{1-x} \mathrm{Co}_{x}\right)_{2} \mathrm{As}_{2}(\mathrm{Ba} 122: \mathrm{Co})$ 一 の $c$ 軸欠陥による $J_{\mathrm{c}}(H \| c)$ の向上 ${ }^{27)}$ や $c$ 軸欠陥と超格子久 陥のハイブリット欠陥導入による磁場中 $J_{\mathrm{c}}$ 特性の向上 ${ }^{28)}$ などが報告されてきた。最近では、 $\mathrm{FeSe}_{0.5} \mathrm{Te}_{0.5}$ 薄膜におい てイオン照射により磁場中特性が向上することが報告され ている ${ }^{29)}$ 。筆者らは、比較的 $T_{\mathrm{c}}$ が高い $\mathrm{BaFe}_{2}\left(\mathrm{As}_{1-x} \mathrm{P}_{x}\right)_{2}$ (Ba122:P) に着目し、PLD 法を用い Ba122:P 薄膜作製を 行ってきた。その結果、 $\mathrm{As} / \mathrm{P}$ 組成、薄膜作製条件を最適 化することで $T_{\mathrm{c}}=28.9 \mathrm{~K} 、 J_{\mathrm{c}}=3 \mathrm{MA} / \mathrm{cm}^{2}$ ( $5 \mathrm{~K}$, 自己磁場) と 高い超伝導特性を示す Ba122:P 薄膜の作製に成功した ${ }^{30)}$ 。 
また、更なる磁場中 $J_{\mathrm{c}}$ 向上に向けて、Ba122:P 薄膜内部に $\mathrm{BaZrO}_{3}(\mathrm{BZO})$ ナノ粒子の導入を試み、その結果、 $5 \mathrm{~K}$ だ けでなく $15 \mathrm{~K}$ においても等方的かつ高い磁場中 $J_{\mathrm{c}}$ を得る ことに成功した ${ }^{31)}$ 。

本稿では、著者らがこれまで作製方法・超伝導材料の異 なる MOD 法 RE123 薄膜及び PLD 法 Ba122:P 薄膜に導入 した BZO ナノ粒子がそれぞれの超伝導薄膜の磁場中超伝 導特性に及ぼす影響について比較しながら、Ba122 系超伝 導薄膜における人工磁束ピンニング点について述べる。

\section{2. 実験結果}

\section{1 ナノ粒子導入 Ba122:P 薄膜の作製及び諸特性}

PLD 法に用いる焼成ターゲットは、 $\mathrm{BaFe}_{2}\left(\mathrm{As}_{0.66} \mathrm{P}_{0.33}\right)_{2}$ 、 $\mathrm{BaFe}_{2}\left(\mathrm{As}_{0.66} \mathrm{P}_{0.33}\right)_{2}+1$ mol.\% $\mathrm{BaZrO}_{3} 、 \mathrm{BaFe}_{2}\left(\mathrm{As}_{0.66} \mathrm{P}_{0.33}\right)_{2}+3$ mol.\% $\mathrm{BaZrO}_{3}$ の 3 種類を作製した。 $\mathrm{Ba}$ 金属 $(99.99 \%$, chunk)、 $\mathrm{Fe}$ 金属 $(99.9 \%$, \#300 mesh pass)、As 粉末 (99.9999\%, $3 \mu \mathrm{m}$ grain) と P 粉末 (99.999\%, \#600 mesh pass) をグローブボックス内で調合し、真空中石英管に封 入し $650^{\circ} \mathrm{C}$ で 10 時間、その後、 $900^{\circ} \mathrm{C}$ で 24 時間焼成し た。 Ba122:P 薄膜 ( 80 nm 膜厚) は、 $\mathrm{MgO}(100)$ 基板上に PLD 用ターゲットを用いて第二高調波 Nd:YAG レーザ (wavelength: $532 \mathrm{~nm}$ ) を用いて $10 \mathrm{~Hz} 、 10^{-4} \mathrm{~Pa} 、 800^{\circ} \mathrm{C}$ で成 膜した。

MOD 法 RE123 薄膜は、 $\mathrm{CeO}_{2} / \mathrm{Y}_{2} \mathrm{O}_{3} / \mathrm{LaMnO}_{3} /$ ion-beamassisted deposition (IBAD)-MgO/ $\mathrm{Gd}_{2} \mathrm{Zr}_{2} \mathrm{O}_{7} /$ Hastelloy $^{\mathrm{TM}} \mathrm{C} 276$ 基 板上に Y-, Gd-, and Ba-trifluoroacetates、Cu-naphthenate を $0.77: 0.23: 1.5: 3$ 比で混合した溶液を塗布、仮焼、本焼成 し作製した。RE123+BZO 薄膜の BZO 添加量は、0 12 vol.\%と変化させ導入した。詳細な焼成条件は、参考文献 25 を参照して頂きたい。

作製した RE123 及び Ba122:P 薄膜の結晶構造及び超伝 導特性評価に X 線回折 (X-ray diffraction, XRD) 法を用い た。 $T_{\mathrm{c}} 、 J_{\mathrm{c}}$ は四端子法を用いて、電気抵抗率の温度依存性 および電流-電圧特性 (閾值 $1 \mu \mathrm{V} / \mathrm{cm}$ ) から算出した。上部 臨界磁場 $\left(H_{\mathrm{c} 2}\right)$ と不可逆磁場 $\left(H_{\mathrm{irr}}\right)$ は、それぞれ $0.90 \rho_{\mathrm{N}}$ and $0.01 \rho_{\mathrm{N}}$ 閾值した ( $\rho_{\mathrm{N}}$ は、常伝導状態の抵抗率)。薄膜 表面観察には、高解像度光学顕微鏡、微細構造観察には走 查透過型電子顕微鏡 (Scanning transmission electron microscopy, STEM)、組成分析をエネルギー分散型 X 線分 光法 (Energy dispersive X-ray spectroscopy, EDX) を用いて 行った。

Fig. 1 に $\mathrm{BaZrO}_{3}$ 添加量に対する (a) $\mathrm{RE} 123$ 及び (b) Ba122:P 薄膜の $c$ 軸方向の結晶性 $(\delta \omega)$ 、面内配向性 $(\delta \phi)$ 、 $T_{\mathrm{c}}$ 及び自己磁場 $J_{\mathrm{c}}\left(J_{\mathrm{c}}\right.$ s.f. $)$ 特性を示す。Fig. 1 より $\mathrm{BZO}$ 添 加量を増加させても RE123+BZO 及び Ba122:P+BZO 薄膜 の両方において結晶性、 $T_{\mathrm{c}, \text { zero }}$ がほぼ変わらないことから、 BZO 導入により母相の結晶性や組成に影響を及ぼさない ことが確認された。一方、 $J_{\mathrm{c}}^{\text {s.f. }}$ は、BZO 添加量を増加に
従って、いずれの超伝導薄膜でも向上していることが分か る。これは $\mathrm{BZO}$ ナノ粒子導入により自己磁場であっても 強いピンニング効果を有するためと考えられる ${ }^{32,33)}$ 。

\section{2 ナノ粒子導入 RE123 及び Ba122:P 薄膜の微細構造}

Fig. 2 に(a) RE123+BZO (12 vol.\%) 及び(b) Ba122:P+BZO (12 vol.\%) 薄膜断面の STEM 像及び Zr 組成分析結果を示 す 31$) 。 Z r$ 組成分析結果より RE123+BZO 及び Ba122:P+BZO 薄膜のいずれにおいても $\mathrm{Zr}$ つまり $\mathrm{BZO}$ ナノ粒子が薄膜全 体に分布していることが分かる。複数の断面 TEM 及び平 面 TEM 像より RE123+BZO 薄膜における BZO ナノ粒子の 平均サイズ $d$ は、 $25 \mathrm{~nm}$ 、密度 $n \sim 50 \times 10^{21} / \mathrm{m}^{3}$ であること が確認された。一方、Ba122:P+BZO 薄膜における BZO ナ ノ粒子の平均サイズ $d$ は、 $8 \mathrm{~nm}$ 、密度 $n \sim 68 \times 10^{21} / \mathrm{m}^{3}$ であ ることが確認された ${ }^{31)}$ 。また、 $\theta-2 \theta$ 測定結果や微細構造 解析における回折パターンより RE123+BZO 及び Ba122:P+BZO 薄膜のいずれにおいても BZO ナノ粒子は、 母相に対してエピタキシャル (整合) ではなくランダム (不整合) であることが確認されている ${ }^{31,34) 。 ~}$

また、Fig. 2 の拡大断面 STEM 像より BZO ナノ粒子 (縦矢印) の周りには、積層欠陥 (横矢印) が確認された。 同様の結果は、異なるナノ粒子材料導入 YBCO 薄膜で確 認されている ${ }^{35)}$ 。これらの積層欠陥は、H $H \mid a b$ におけるピ ンニング点として知られている。

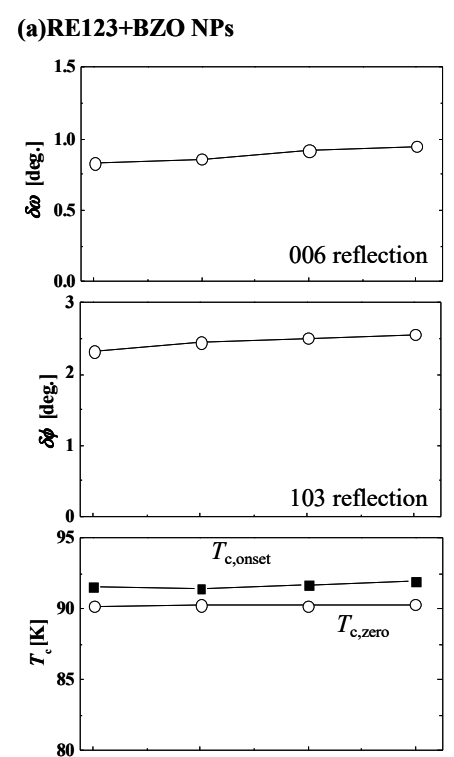

(b)Ba122:P+BZO NPs
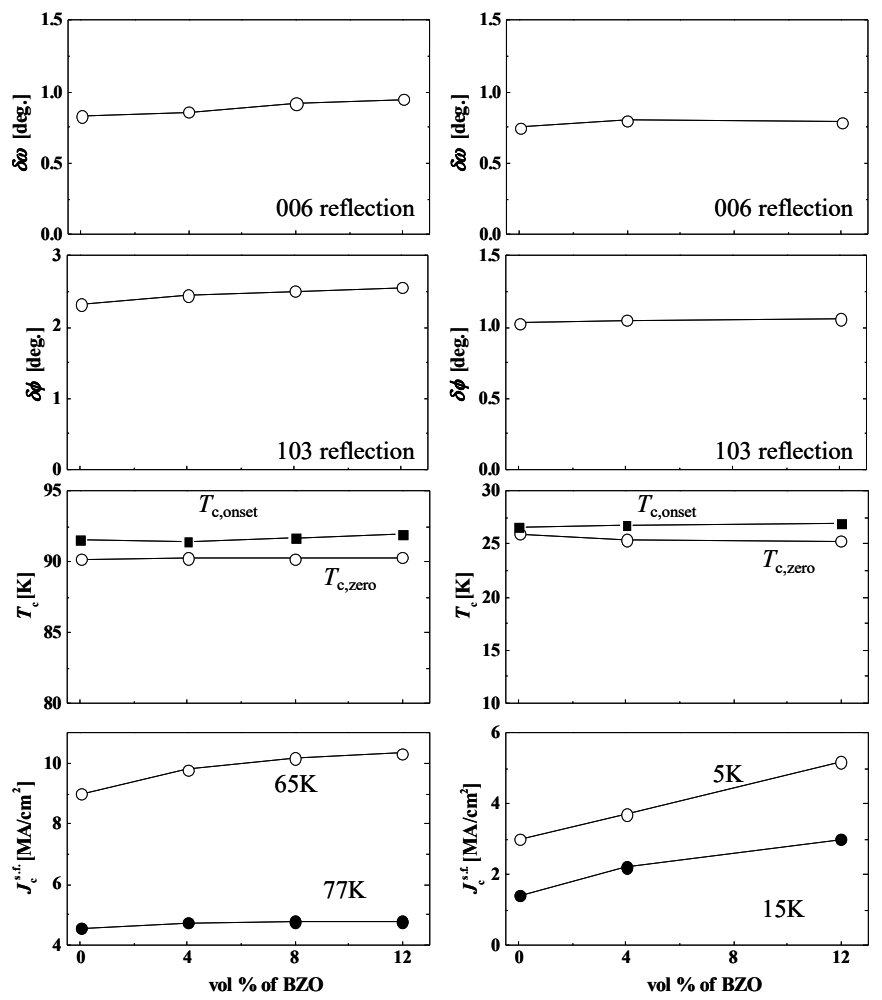

Fig. 1 Structural and superconducting properties for (a) RE123+BZO and (b) Ba122:P+BZO NPs films. 
(a) RE123+BZO NPs
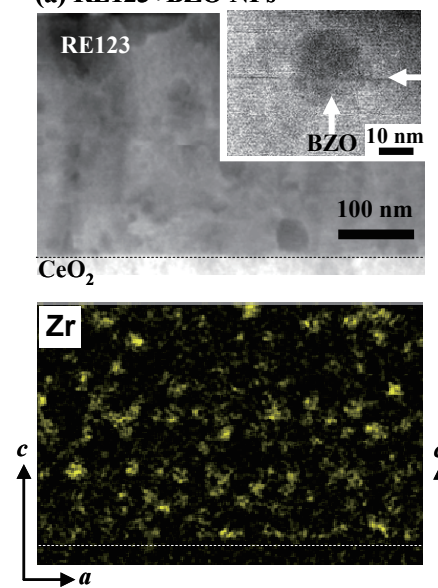

(b) Ba122:P+BZO NPs
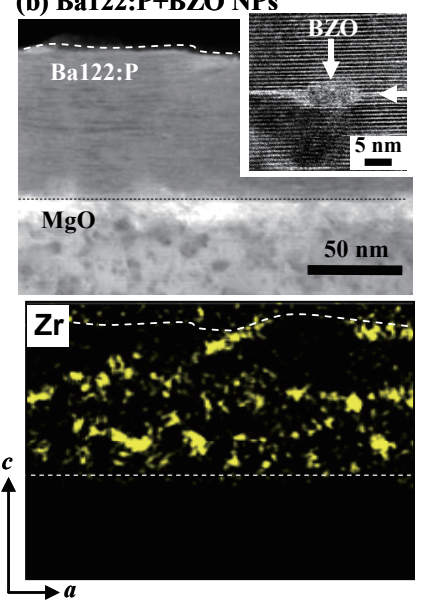

Fig. 2 Cross-sectional STEM images and elemental maps of Zr for (a) RE123+BZO and (b) Ba122:P+BZO NPs films ${ }^{31}$. (a) RE123+BZO NPs

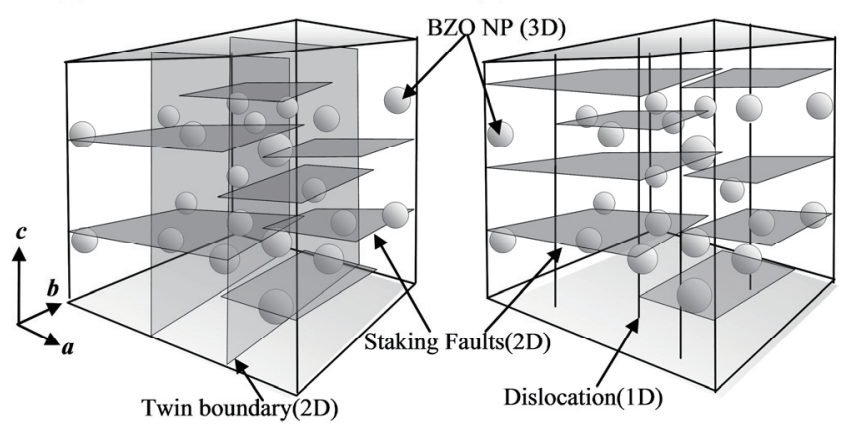

Fig. 3 Schematic images of microstructure for (a) RE123+BZO and (b) Ba122:P+BZO NPs films.

Fig. 3 に微細構造観察より得られた (a) RE123+BZO 及び (b) Ba122:P+BZO 薄膜における磁束ピンニング点の候補と なる久陷を示す。RE123+BZO 薄膜は、Fig. 3(a)に示すよ うに BZO ナノ粒子の他に、 $c$ 軸相関ピンニング点である 双晶欠陷、 $a b$ 面ピンニング点である積層欠陥が存在す る 25)。一方、Ba122:P+BZO 薄膜には、BZO ナノ粒子以外 に柱状成長する PLD 薄膜にナチュラルに導入される転位 が存在する (Fig. 3(b))。特にスパイラル成長により成長し た薄膜には、刃状転位の他に螺旋転位が存在する ${ }^{36) か ゙ 、 ~}$ 本研究で作製した Ba122:P+BZO 薄膜は、スパイラル成長 でないため、刃状転位が主な $c$ 軸相関ピンニング点と考え られる ${ }^{37)}$

\section{3 ナノ粒子導入 RE123 及び Ba122:P 薄膜の臨界磁場}

Fig. 4に (a) RE123+BZO (12 vol.\%) 及び(b) Ba122:P+BZO (12 vol.\%) 薄膜の $H\|c 、 H\| a b$ における臨界磁場 $\left(H_{\mathrm{c} 2}\right)$ 及び 不可逆磁場 $\left(H_{\mathrm{irr}}\right)$ の温度依存性を示す25,31)。 $H_{\mathrm{c} 2}$ に着目する とRE123+BZO及びBa122:P+BZO薄膜のいずれにおいても $\mathrm{BZO}$ ナノ粒子を導入していない薄膜と微細構造が異なるに もかかわらず非常に似た $H_{\mathrm{c} 2}-T$ 特性を示すことが分かる。
また、超伝導異方性パラメータ $\left(\gamma_{\mathrm{H}}=H_{\mathrm{c} 2}(a b) / H_{\mathrm{c} 2}(c)\right)$ を求 めた結果、RE123薄膜においては、BZOナノ粒子の有無に 関わらずに $\gamma_{\mathrm{H}} \sim 5\left(t=T / T_{\mathrm{c}}=0.9\right)$ を示すことが確認されてい る25)。また、Ba122:P薄膜においても、BZOナノ粒子の有 無に関わらずに $\gamma_{\mathrm{H}} \sim 1.55\left(t=T / T_{\mathrm{c}}=0.9\right)$ を示し、 $H_{\mathrm{c} 2}$ の角度依 存性特性と非常によく一致することが確認された ${ }^{31)}$ 。この ようにいずれの超伝導材料においても人工欠陥として非超 電導相を導入した際に、母相のキャリア濃度に大きな影響 を及ぼさない場合には、微細構造が異なっても $H_{\mathrm{c} 2}$ は変化 しないことが分かる。

一方、実用上の臨界磁場となる $H_{\mathrm{irr}}$ は、人工欠陥の有無 によって異なる特性を示す。 $H_{\mathrm{irr}}$ が高いことは、 $J_{\mathrm{c}} \neq 0$ つ まり実用できる領域が広いことを意味する。 $H_{\mathrm{irr}}$ に着目す ると RE123+BZO 及び Ba122:P+BZO 薄膜のいずれにおい ても $\mathrm{BZO}$ ナノ粒子を導入していない薄膜に比べて、 $H \| a b$ においても $H_{\mathrm{irr}}$ の向上を示すが、H\|c においては高い $H_{\mathrm{irr}}$ を示すことが確認された。 $H \| c$ と $H \| a b$ での $H_{\mathrm{irr}}$ の向上率 が違う理由としては、2.4 節で述べる $J_{\mathrm{c}}$ の磁場印加角度依 存性と同様の傾向を示すことからピンニング力の違いによ るものだと考えられる。その要因として(1) $H \| c$ と $H \| a b$ における $\mathrm{BZO}$ ナノ粒子による磁束ピンニング力の違いと (2) $H \| c$ と $H \| a b$ におけるナチュラル欠陥の違いが考えられ る。(1)に関しては、 $H \| c$ では量子化磁束は、 $2 \xi_{\mathrm{ab}}$ の直径 を有する円柱であり、パスタの形状で表すとスパゲッティ 形状に対して $H \| a b$ では、 $2 \varepsilon(\theta) \xi_{\mathrm{ab}}$ (c 軸方向) と $2 \xi_{\mathrm{ab}}(a b$ 面方向) とパスタの形状で表すとリングイーネのような形 状に量子化磁束の形状が変化する。ここで $\varepsilon(\theta)$ は、超伝導
(a)Ba122:P+BZO NPs
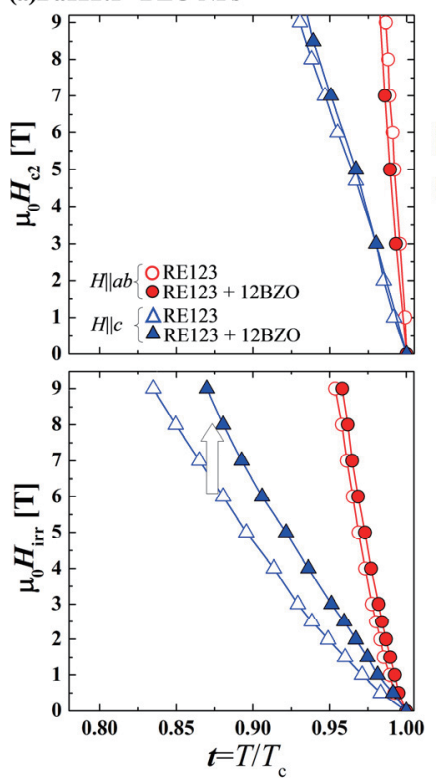

(b)Ba122:P+BZO NPs
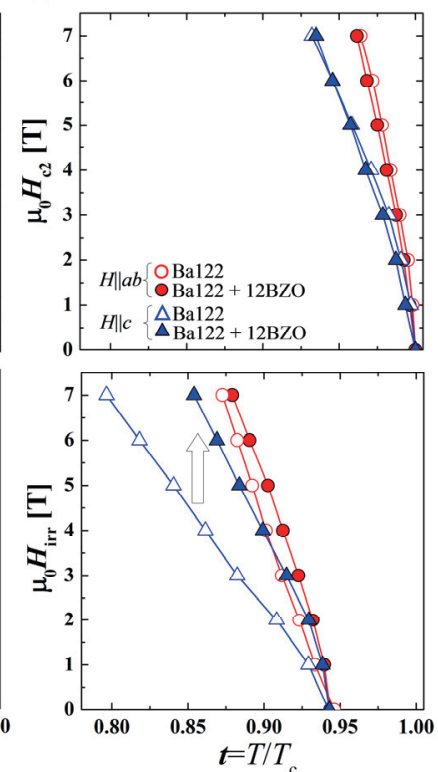

Fig. 4 Normalized temperature $\left(t=T / T_{\mathrm{c}}\right)$ dependence of $H_{\mathrm{c} 2}$ and $H_{\text {irr }}$ for (a) RE123+BZO and (b) Ba122:P+BZO NPs films. 
異方性パラメータ $\gamma$ を用いて $\varepsilon(\theta)=\left[\cos ^{2}(\theta)+\gamma^{-2} \sin ^{2}(\theta)\right]^{0.5}$ と 表すことができる。量子化磁束の形状変化に対して BZO ナノ粒子は、等方的で磁場印加角度に対して変わらない。 そのため、異方性が大きいほど磁場印加角度に対して量子 化磁束の形状変化が大きく、等方的な BZO ナノ粒子の磁 束ピンニング点としての効果が変化し、H\|ab で最もピン ニングカが小さくなるためと考えられる。詳細は、参考文 献 26 を参照していただきたい。もう一つの要因である(2) は、Fig. 3 に示したように RE123+BZO 及び Ba122:P+BZO 薄膜のいずれにおいても存在する $c$ 軸相関ピンニング点で ある双晶欠陥 (or 刃状転位) と $a b$ 面ピンニング点である積 層欠陥の形状の違いが影響していると考えられる。 $H \| c$ で は、双晶欠陥 (or 刃状転位) $+\mathrm{BZO}$ ナノ粒子、 $H \| a b$ では、 積層欠陥+BZO ナノ粒子のハイブリット欠陥が有効な磁束 ピンニング点となる。双晶欠陥と刃状転位は、基板直上か ら薄膜表面までつながった $c$ 軸相関ピンニング点であるの に対して、積層欠陥は Fig. 3 に示すようにいずれの RE123、 Ba122:P 薄膜においても端から端までつがっておらず途切 れて存在する。つながって存在する双晶欠陥や刃状転位に 比べて、つながっていない積層欠陥は、BZO ナノ粒子に よってピン止めされている磁束以外の磁束をピン止めする ピンニング点としてはピンニングカが弱いことが考えられ る。

\section{4 ナノ粒子導入 RE123 及び Ba122:P 薄膜の磁場中 $J_{0}$ 特性}

現在、燃料電池自動車の開発により水素ステーションに 水素を液体水素 $(20.3 \mathrm{~K})$ で貯めることが計画され、一部 のステーションでは試験的に実施されている。もし仮に、 鉄系超伝導線材の $20.3 \mathrm{~K}$ における磁場中 $J_{\mathrm{c}}$ 特性が $\mathrm{NbTi}$ $(4.2 \mathrm{~K})$ と同程度の特性を得ることができれば、水素が拓 く低炭素かつエネルギー高効率利用社会に貢献する発電機、 電力貯蔵装置、送電ケーブル、変圧器などの機器へ応用が 可能と考えられる。現在、鉄系超伝導材料の磁場中特性は、 $4.2 \mathrm{~K}$ での測定結果に関するものが多いが、鉄系超伝導の 応用を考えると $4.2 \mathrm{~K}$ ではなく $20.3 \mathrm{~K}$ に近い温度で $\mathrm{NbTi}$ $(4.2 \mathrm{~K})$ などの実用線材にどれだけ近づけられるかが鍵と なる。本稿では、過泠却液体水素温度に近い $15 \mathrm{~K}$ での Ba122:P 薄膜の磁場中 $J_{\mathrm{c}}$ 特性について述べたいと思う。

Fig. 5 に (a) RE123+BZO 及び(b) Ba122:P+BZO 薄膜の磁 場中 $J_{\mathrm{c}}$ 特性 $(H \| c)$ を示寸 $\left.{ }^{31}\right)$ 。比較のために $\mathrm{NbTi}$ 線材 $(4.2 \mathrm{~K})^{38)} 、 \mathrm{MgB}_{2}$ 薄膜 $(15 \mathrm{~K})^{39)}$ 、超格子久陷導入 $\mathrm{Ba} 122: \mathrm{Co}$ 薄膜 $(16 \mathrm{~K})^{28)}$ の特性もプロットした。

RE123+BZO 薄膜に着目すると、RE123 薄膜に比べて すべての磁場においても高い磁場中 $J_{\mathrm{c}}$ 特性を示す。また、 $2 \mathrm{~T}$ 程度まで $\mathrm{NbTi}$ 線材 $(4.2 \mathrm{~K})$ や $\mathrm{MgB}_{2}$ 薄膜 $(15 \mathrm{~K})$ と同 等程度の高い磁場中 $J_{\mathrm{c}}$ 特性であることが分かる。

一方、Ba122:P+BZO 薄膜は、Ba122:P 薄膜や超格子欠陥 導入 Ba122:Co 薄膜 $(16 \mathrm{~K})$ の特性 ${ }^{28)}$ よりも十分高い磁場
中 $J_{\mathrm{c}}$ 特性を示した。また、 $15 \mathrm{~K}$ において $\mathrm{NbTi}$ 線材 $(4.2$ $\mathrm{K})$ や $\mathrm{MgB}_{2}$ 薄膜 $\left(15 \mathrm{~K}, \mu_{0} H>1 \mathrm{~T}\right)$ より高い磁場中 $J_{\mathrm{c}}$ 特性 を示したことは、これらに代わる超伝導材料として期待で きることを意味する。

超伝導線材の磁場応用を考えた場合、ソレノイドコイル などのコイルにすることが想定される。これらに適した超 伝導線材としては、磁場印加角度に対して等方的かつ高い $J_{\mathrm{c}}$ を有する材料が求められる。異方性は異なるが、Ba122 材料 $\left(\gamma_{\mathrm{H}} \sim 1.5\right)$ は、RE123 材料 $\left(\gamma_{\mathrm{H}} \sim 5\right)$ 同様に $H \| c$ での $J_{\mathrm{c}}$ が最低值を示すため、 $c$ 軸方向に人工欠陥を導入する研究 がはじめに行われたが、 $H \| c$ での $J_{\mathrm{c}}$ は向上するが、 $J_{\mathrm{c}, \text { min }}$ はそれほど向上しないことが確認されていた ${ }^{27,28) 。 そ こ て ゙ 、 ~}$ 等方的な形状を有寸る BZO ナノ粒子が $J_{\mathrm{c}}$ の磁場印加角度 依性に及ぼす影響を調べた。Fig. 6 に (a) RE123+BZO (77 $\mathrm{K}, 1 \mathrm{~T})$ 及び (b) Ba122:P+BZO $(15 \mathrm{~K}, 1 \mathrm{~T})$ 薄膜 ${ }^{31)}$ の $J_{\mathrm{c}}$ の磁 場印加角度依存性を示す。図より RE123+BZO 薄膜は、 RE123 薄膜に比べて等方的かつすべての磁場印加角度に おいても高い $J_{\mathrm{c}}$ 特性を示す。一方、Ba122:P+BZO 薄膜も Ba122 薄膜に比べて等方的かつ高い $J_{\mathrm{c}}$ 特性を示寸ことが 分かる。また、 $15 \mathrm{~K} 、 1 \mathrm{~T}$ において $J_{\mathrm{c}, \max }$ ではなく $J_{\mathrm{c}, \min }$ で

\section{(a) RE123+BZO NPs}

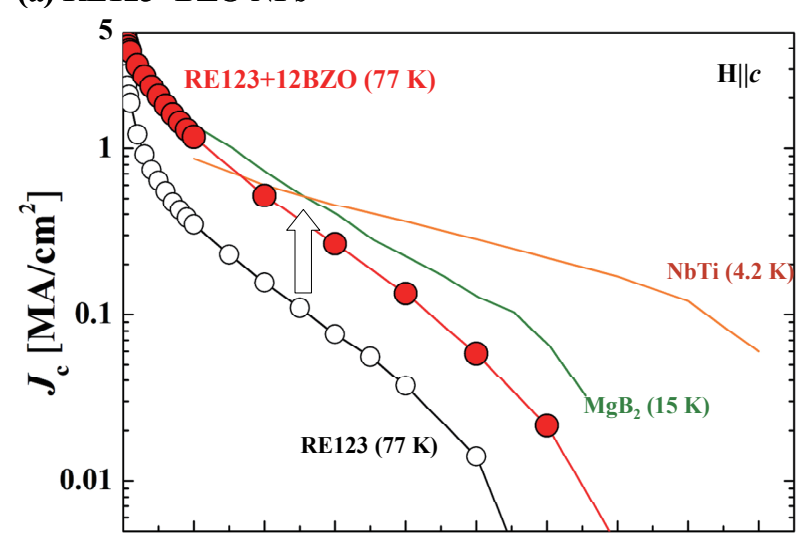

(b) Ba122:P+BZO NPs

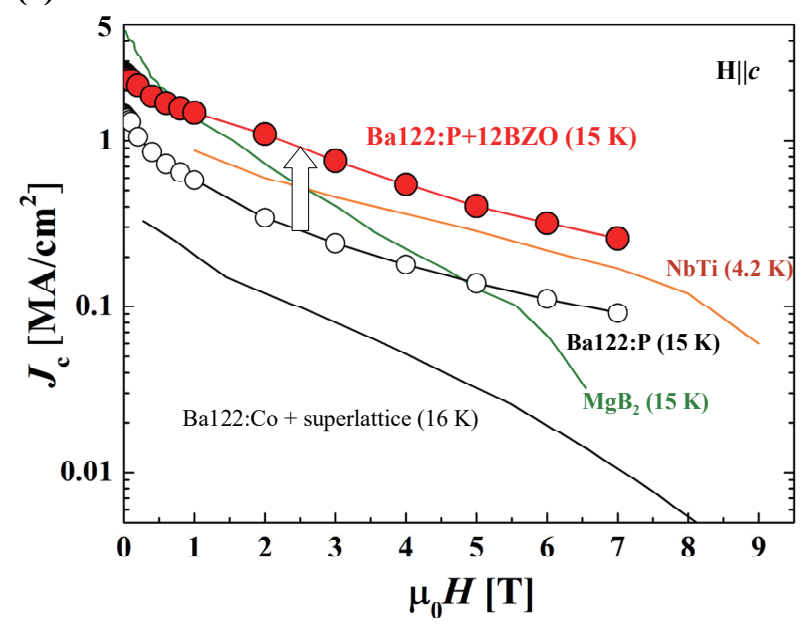

Fig. $5 \quad J_{\mathrm{c}}(H \| c)$ for (a) RE123+BZO (77 K) and (b) Ba122:P+BZO NPs films (15 K). 


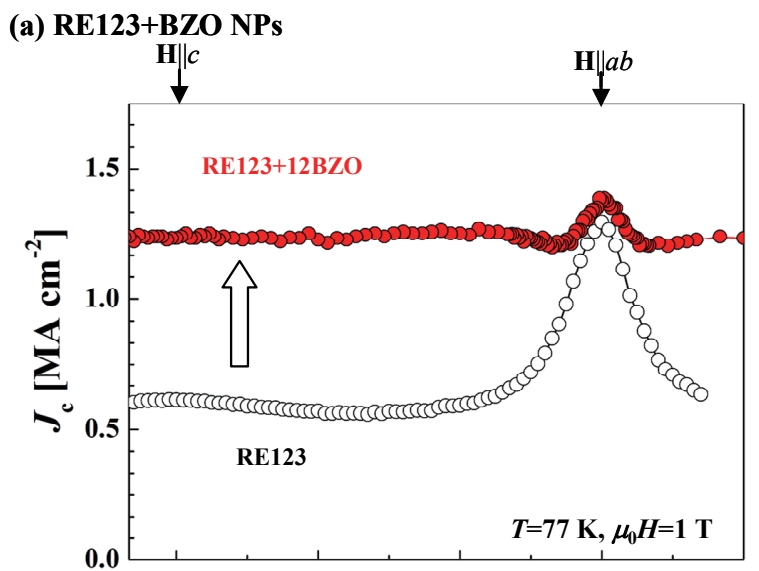

(b) Ba122:P+BZO NPs

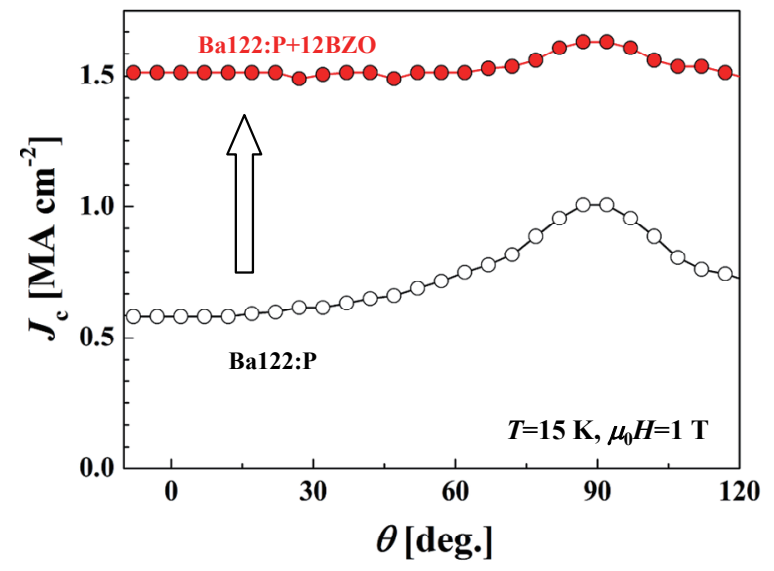

Fig. 6 Angular dependence of $J_{\mathrm{c}}$ for (a) RE123+BZO (77 $\mathrm{K}, 1 \mathrm{~T}$ ) and (b) Ba122:P+BZO NPs films (15 K, $1 \mathrm{~T})$.

$1.5 \mathrm{MA} / \mathrm{cm}^{2}$ を超える非常に高い $J_{\mathrm{c}}$ を得たことは、鉄系へ の人工欠陥導入が磁場中 $J_{\mathrm{c}}$ 向上に有効な手段であること を意味する。以上のことより RE123 及び Ba122:P 薄膜の いずれにおいても BZO ナノ粒子がすべての磁場印加角度 に対しても磁束ピンニング点として有効であることが分 かった。また、各角度における $\mathrm{BZO}$ ナノ粒子のピンニン グ力の違いについて 2.3 節で述べたとおりである。

\section{5 ナノ粒子による磁束ピンニング解析ツール}

応用に適した磁場中特性をデザインするためには、どの ような磁束ピンニング点が必要かを解析する必要がある。 そのひとつの手法として、導入前の磁場中 $J_{\mathrm{c}}$ 特性 $\left(J_{\mathrm{c}, \mathrm{standard}}\right)$ に対して導入後の磁場中 $J_{\mathrm{c}}$ 特性 $\left(J_{\mathrm{c}, \mathrm{defect}}\right)$ の向上 率 $\left(\Delta J_{\mathrm{c}}=J_{\mathrm{c}, \text { defect }} / J_{\mathrm{c}, \text { standard }}\right)$ の計算が挙げられる。

Fig. 7(a)に $t=T / T_{\mathrm{c}}=0.20$ と $t=0.60$ における Ba122:P の $\Delta J_{\mathrm{c}}\left(=J_{\left.\mathrm{c}, \mathrm{BZO} / J_{\mathrm{c}, \text { standard }}\right)}\right.$ の磁場依存性を示す 31$)$ 。比較のため に同様の $t$ における RE123 薄膜の $\Delta J_{\mathrm{c}}\left(=J_{\mathrm{c}, \mathrm{BZO}} / J_{\mathrm{c}, \text { standard }}\right)$ の磁 場依存性を示す。Ba122:P 薄膜における $t=0.20$ 及び $t=0.60$ での $\Delta J_{\mathrm{c}}$ の磁場依存性は非常に似た特性を示すことが分か る。更に、最大の $\Delta J_{\mathrm{c}}$ を示す磁場 $\left(\mu_{0} H\left(\Delta J_{\mathrm{c}, \max }\right)\right)$ がいずれ の温度においても $3.5 \mathrm{~T}$ であることが確認された。一方、 RE123 薄膜における $t=0.20$ 及び $t=0.60$ での $\Delta J_{\mathrm{c}}$ の磁場依存 (a)

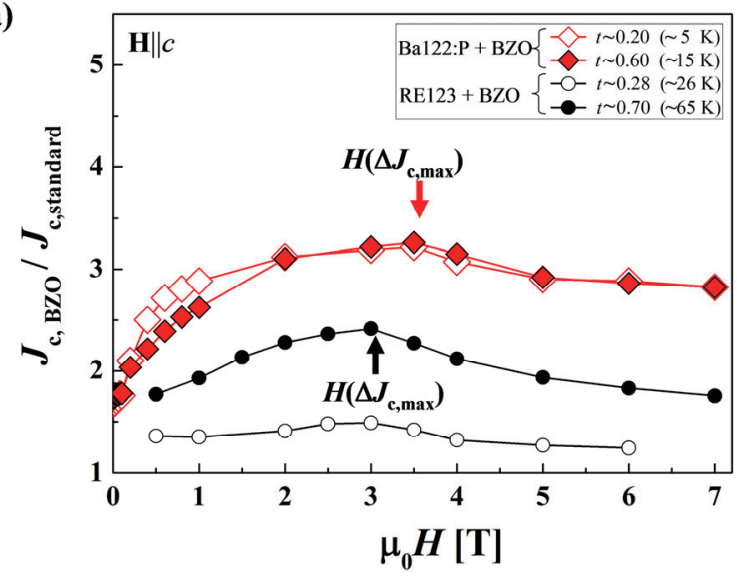

(b)

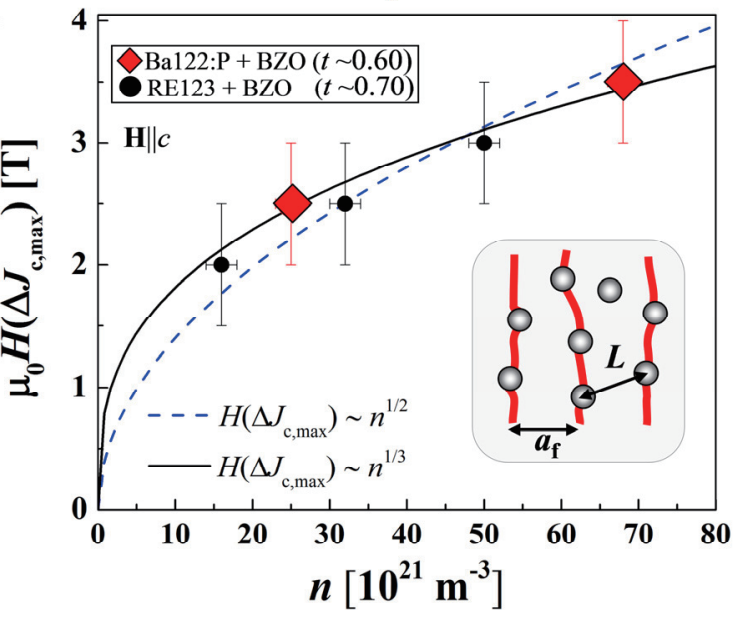

Fig. 7 (a) The $J_{\mathrm{c}}$ ratio $\left(\Delta J_{\mathrm{c}}=J_{\mathrm{c}, \mathrm{BZO}} / J_{\mathrm{c} \text {, standard }}\right)$ for Ba122:P films at $H \| c$. For comparison, the data for RE123 films are included. (b) Solid and open symbols are $H\left(\Delta J_{\mathrm{c} \text {,max }}\right)$ at $H \| c$ for Ba122:P films at $t \sim 0.60$ and RE123 films at $t \sim 0.70$. Inset: Schematic of a possible configuration of each vortex line is pinned by an array of nanoparticles ${ }^{31}$.

性は非常に異なる特性であることが分かる。高温 $(t=0.60)$ では、向上率が高く、その最大の $\Delta J_{\mathrm{c}}$ を示す磁場 $\left(\mu_{0} H\left(\Delta J_{\mathrm{c}, \max }\right)\right)$ が $3 \mathrm{~T}$ であるのに対して、低温では、向上率 が非常に低いことが確認された。これらの結果より RE123 薄膜における BZO ナノ粒子よりも Ba122:P 薄膜に おける BZO ナノ粒子の方が広い温度範囲で有効に磁束の 運動を抑制していることが分かる。これらの違いは、BZO ナノ粒子のサイズの違いで理解できる。Ba122:P 薄膜内部 における $\mathrm{BZO}$ ナノ粒子の平均サイズ $d \sim 8 \mathrm{~nm}$ である。こ れに対して、 $5 \mathrm{~K}$ 及び $15 \mathrm{~K}$ における磁束のサイズ $\left(2 \xi_{a b}\right)$ は、それぞれ $5 \mathrm{~nm}\left(d / 2 \xi_{a b}=1.6\right) 、 8 \mathrm{~nm}\left(d / 2 \xi_{a b}=1.0\right)$ と $5 \sim 15 \mathrm{~K}$ 範囲で磁束をピンニングするに適したナノ粒子 サイズである。

一方、RE123 薄膜における BZO の平均サイズ $d \sim 25 \mathrm{~nm}$ である。 $65 \mathrm{~K}$ における磁束のサイズ $\left(2 \xi_{a b}\right)$ は、8.1 nm $\left(d / 2 \xi_{a b}=3.1\right)$ とまだ有効なサイズであると考えられる。し かし、低温である $26 \mathrm{~K}$ では磁束サイズは、 $5 \mathrm{~nm}$ であり、 $\mathrm{BZO}$ ナノ粒子のサイズは 5 倍である。ナノ粒子密度が 
$n \sim 5 \times 10^{22} / \mathrm{m}^{3}$ と高密度であっても、サイズが大きい場合 には、ナノ粒子内で磁束が動くためピンニング効果が低く なると考えられる。これらの結果より、導入するナノ粒子 のサイズは、必要とする温度での磁束サイズの 0.7 倍から 3 倍程度が有効なサイズと考えられる 26)。

次に、最大の $\Delta J_{\mathrm{c}}$ を示す磁場 $\left(\mu \mu_{0} H\left(\Delta J_{\mathrm{c}, \max }\right)\right)$ に着目する。 Fig. 7(a)より $t=0.20$ 及び $t=0.60$ における Ba122:P 薄膜の $\mu_{0} H\left(\Delta J_{\mathrm{c}, \max }\right)$ は、いずれにおいても $3.5 \mathrm{~T}$ である。3.5 T に おける磁束間距離 $a_{\mathrm{f}} \sim 26 \mathrm{~nm}$ と $\mathrm{BZO}$ ナノ粒子ナノ粒子同 士の間隔 $L \sim 24 \mathrm{~nm}$ とほぼ同程度である。 RE123 薄膜にお いて BZO ナノ粒子密度が増えると $\Delta J_{\mathrm{c}}$ が向上するだけでな く、 $\mu_{0} H\left(\Delta J_{\mathrm{c}, \max }\right)$ の值も増加することが確認されている ${ }^{31) 。}$ これらのことより $\mu_{0} H\left(\Delta J_{\mathrm{c}, \text { max }}\right)$ は、ナノ粒子密度と相関が あることが分かる。Fig. 7(b)に Ba122:P 薄膜 $(t \sim 0.60)$ and $\mathrm{RE} 123$ 線材 $(t \sim 0.70)$ における $\mu_{0} H\left(\Delta J_{\mathrm{c}, \max }\right)$ と BZO ナノ粒 子密度の関係を示す。いずれの超伝導材料においても $\mu_{0} H\left(\Delta J_{\mathrm{c}, \max }\right) \sim n^{1 / 3 \sim 1 / 2}$ の関係が成り立つことが分かる。特に $\mu_{0} H\left(\Delta J_{\mathrm{c}, \max }\right) \sim n^{1 / 2}$ は、 $a_{\mathrm{f}} \sim L$ の磁場において最大の $\Delta J_{\mathrm{c}}$ を示 すことを意味する (Fig. 7(b)の挿入図参照)。この関係は、

Koshelev らによるナノ粒子による理論計算より得られた 密度と磁束間隔の関係式と一致する ${ }^{40)}$ 。

以上のようにナノ粒子による磁束ピンニング特性は、ナ ノ粒子のサイズ・密度と量子化磁束の異方性・サイズとの バランスで決まり、ナノ粒子サイズは $0.7 \leq d / 2 \xi_{a b} \leq 3^{26) 、}$ ナノ粒子密度は、応用磁場に対して $\mu_{0} H\left(\Delta J_{\mathrm{c}, \max }\right) \sim n^{1 / 3 \sim 1 / 2}$ と なるように結晶性、組成に影響を与えずに超伝導薄膜・線 材内に導入するのが望ましいと考えられる。

\section{6 ナノ粒子導入 RE123 及び Ba122:P 薄膜の磁束ク リープ特性}

一般的に、超伝導体における $J_{\mathrm{c}}$ は時間とともに減少す る。この時、磁束クリープレート (磁束の熱振動) $S$ は $S=-\mathrm{d} \ln (J) / \mathrm{d} \ln (t)$ と表すことができ、実験的に求めること ができる。理想的には、この值が小さいほど、超伝導マグ ネットを作った際に、永久電流モードで使用することがで き、応用上重要なパラメータとなる。

Fig. 8 に (a) RE123+BZO $(77 \mathrm{~K}, H \| 0.3 \mathrm{~T})^{41)}$ 及び (b) $\mathrm{Ba} 122: \mathrm{P}+\mathrm{BZO}(15 \mathrm{~K}, H \| 1 \mathrm{~T}, 1.5 \mathrm{~T})^{42)}$ 薄膜の磁束クリープ レートの温度依存性 $(H \| c)$ を示す。 RE123+BZO 及び Ba122:P+BZO 薄膜のいずれにおいても BZO ナノ粒子を導 入していない薄膜に比べて、低い磁束クリープ特性を示す。 これらのことより鉄系超伝導材料においても人工欠陥であ る $\mathrm{BZO}$ ナノ粒子導入により磁束の熱振動を抑制したため と考えられる。

Fig. 9 に様々な超伝導材料の $t=0.25 、 1 \mathrm{~T}(H \| c)$ におけ る磁束クリープレートのギンツブルグ数 $\left(G_{\mathrm{i}} \propto \gamma^{2} T_{\mathrm{c}}^{2} \lambda^{4} / \xi^{2}\right)$ 依存性を示寸 ${ }^{42)}$ 。図より分かるように $\mathrm{NbTi} 、 \mathrm{Nb}_{3} \mathrm{Sn}$ 、 $\mathrm{MgB}_{2}$ などの金属系超伝導体は、G $G_{\mathrm{i}}$ が小さく、磁束クリー プが小さいため、実際に永久電流モードでのマグネット忘 (a) RE123+BZO NPs

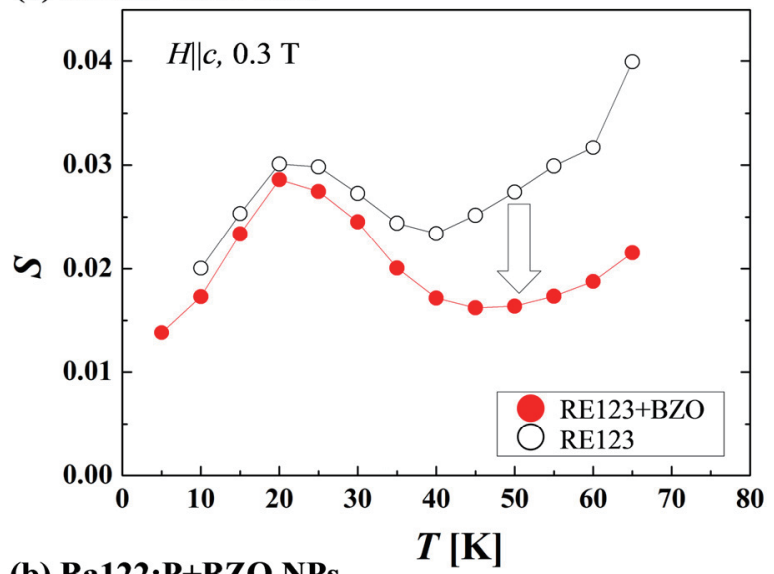

(b) Ba122:P+BZO NPs

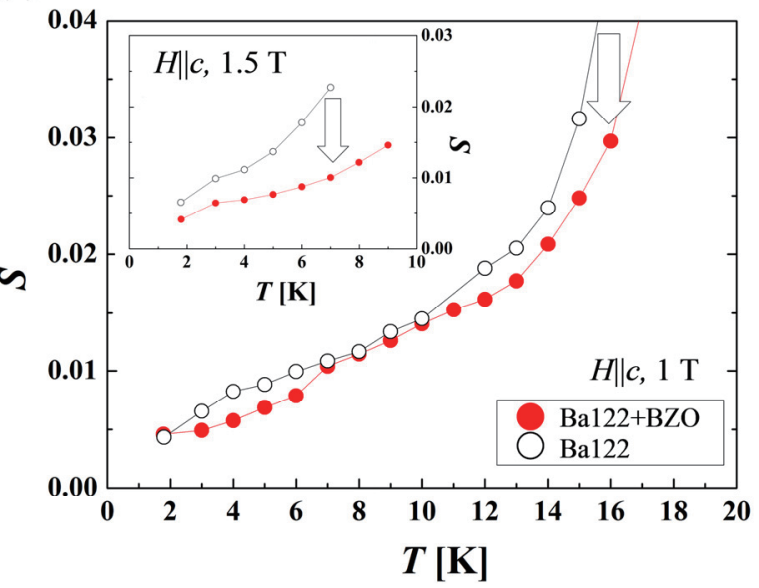

Fig. 8 Temperature-dependent creep rate $(S)$ for (a) RE123+BZO (77 K, $H \| 0.3 \mathrm{~T})$ and (b) Ba122:P+BZO NPs films $(15 \mathrm{~K}, H \| 1 \mathrm{~T}, 1.5 \mathrm{~T})^{42)}$.

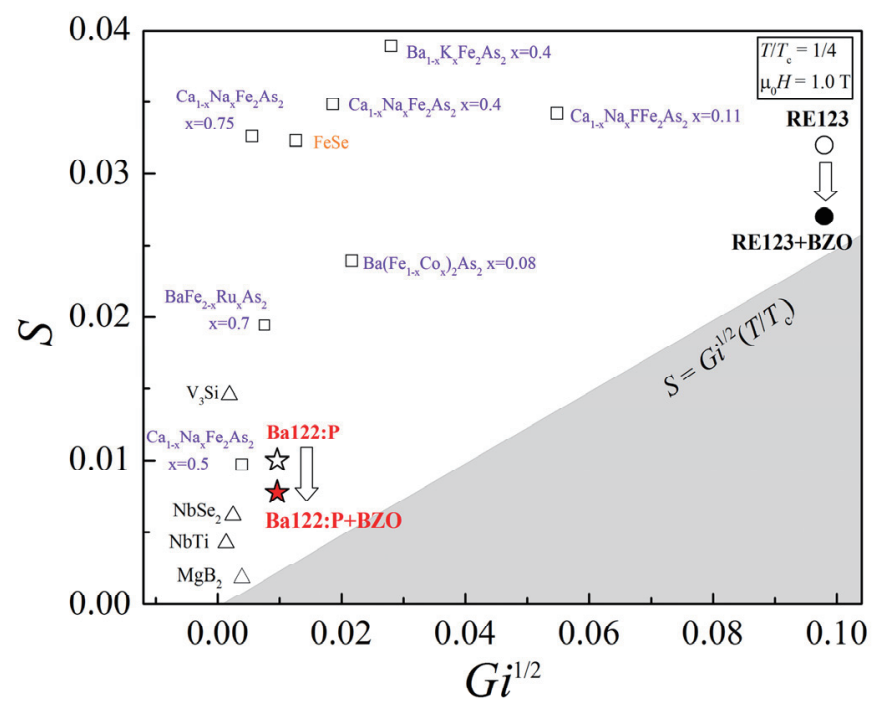

Fig. 9 Creep at reduced temperature $T / T_{\mathrm{c}}=1 / 4$ and field of $\mu_{0} H$ $=1 \mathrm{~T}$ for different superconductors plotted versus $G i^{1 / 2}$. The solid symbols indicate materials for which the microstructure has been modified by either irradiation or incorporation of inclusions. The solid gray line represents the limit set by $G i^{1 / 2} T / T_{\mathrm{c}}=G i^{1 / 2} / 4^{42)}$. 
用が実現している。一方、図より RE123 のように $G$ i が大 きい材料は、BZO ナノ粒子を磁束ピンニング点を導入し た RE123+BZO 薄膜においても磁束クリープレートが他 の金属系超伝導体に比べても高く、磁束クリープを下げる には限界があることが分かってきた ${ }^{42)}$ 。

初期の $\left(\mathrm{Ca}_{1-x} \mathrm{Na} x\right) \mathrm{Fe}_{2} \mathrm{As} 2$ や $\mathrm{Ba} 122: \mathrm{K}$ を含む 122 系鉄超伝 導材料では、組成制御の難しさや結晶性の問題から磁束ク リープが比較的大きいことが確認されていた。しかし、最 近、筆者らが組成・結晶性を制御し作製した Ba122:P 薄膜 は、他の Ba122 に比べて非常に小さい磁束クリープ特性 を示すことが確認された。更に、図から分かるように Ba122:P+BZO 薄膜は、BZO ナノ粒子を導入することで $\mathrm{NbTi}$ の值に近い值まで磁束クリープを低減することに成 功した。

\section{3. おわりに}

本稿では、筆者らが取り組んできた鉄系超伝導薄膜への 人工ナノ粒子導入による磁場中特性向上に関寸る研究結果 について Y 系超伝導薄膜と比較しながら紹介した。鉄系 超伝導体は、 $\mathrm{LaFeAsO}\left(T_{\mathrm{c}}=26 \mathrm{~K}\right)$ の発見から来年でちょう ど 10 年になる。既に Ba122 に関しては PIT 法による線材 化、PLD 法によるコート線材化など研究が行われている。 もし、これらの鉄系超伝導線材の磁場中特性が液体水素温 度 $(20.3 \mathrm{~K})$ で、 $4.2 \mathrm{~K}$ で実用されている金属系超伝導材料 を超える特性が得られれば、これらに代わる材料となると 期待されている。今回、紹介したように Ba122 材料は人 工欠陥導入により $J_{\mathrm{c}}$ 特性の向上や磁束クリープの低減が 可能であることが証明された。また、最近では、高品質な Ba122:Co 薄膜 ${ }^{43)}$ や本研究同様に BZO 導入による $\mathrm{Ba} 122: \mathrm{Co}$ 薄膜の磁場中 $J_{\mathrm{c}}$ 向上 ${ }^{44)}$ が報告されている。今後、 鉄系超伝導材料である 11 型、111 型、1111 型などの Ba122 とは異なる結晶構造でも人工欠陥導入による磁束ピ ンニング研究が進むことによって、鉄系超伝導材料全体の 更なる特性向上につながると期待できる。

本研究の鉄系超伝導体に関する研究の一部は、日本学術 振興会 最先端研究開発支援プログラム (FIRST プログラ ム) からの支援により、国際超電導産業技術研究センター (現：超電導センシング技術研究組合) の田辺圭一所長の 研究グループとの共同研究で行われたものである。また、 成蹊大学における鉄系超伝導体に関する研究は、日本学術 振興会 科学研究費助成事業・若手研究 (A) (No. 26709076) から研究支援を受け実施した。また、米国ロスアラモス国 立研究所における鉄系超伝導体に関寸る研究は、米国エネ ルギー省 (DOE), Basic Energy Sciences (BES)、Materials Sciences and Engineering Divisionの支援を受けて実施した ものである。鉄系超伝導体に関する共同研究者である田辺 圭一博士、安達成司博士、Dr. Boris Maiorov、Dr. Serena
Eley、Dr. Leonardo Civale に感謝申し上げる。

\section{参 考 文 献}

1) Y. Kamihara, et al.: "Iron-based layered superconductor: LaOFeP,” J. Am. Chem. Soc. 128 (2006) 10012

2) Y. Kamihara, et al.: "Iron-based layered superconductor $\mathrm{La}\left[\mathrm{O}_{1-x} \mathrm{~F}_{x}\right] \mathrm{FeAs}(x=0.05-0.12)$ with $T_{\mathrm{c}}=26 \mathrm{~K}$," J. Am. Chem. Soc. 130 (2008) 3296

3) M. Putti, et al.: "New Fe-based superconductors: properties relevant for applications," Supercond. Sci. Technol. 23 (2010) 034003

4) T. Katase, et al.: "Biaxially textured cobalt-doped $\mathrm{BaFe}_{2} \mathrm{As}_{2}$ films with high critical current density over $1 \mathrm{MA} / \mathrm{cm}^{2}$ on $\mathrm{MgO}$-buffered metal-tape flexible substrates," Appl. Phys. Lett. 98 (2011) 242510

5) K. Iida, et al.: "Epitaxial growth of superconducting $\mathrm{Ba}\left(\mathrm{Fe}_{1-x} \mathrm{Co}_{x}\right)_{2} \mathrm{As}_{2}$ thin films on technical ion beam assisted deposition $\mathrm{MgO}$ substrates,” Appl. Phys. Express. 4 (2011) 013103

6) H. Hiramatsu, et al: "Critical factor for epitaxial growth of cobaltdoped $\mathrm{BaFe}_{2} \mathrm{As}_{2}$ films by pulsed laser deposition," Appl. Phys. Lett. 104 (2014) 172602

7) T. Kawaguchi, et al: "The strain effect on the superconducting properties of $\mathrm{BaFe}_{2}(\mathrm{As}, \mathrm{P})_{2}$ thin films grown by molecular beam epitaxy," Supercond. Sci. Technol. 27 (2014) 065005

8) For a review, D. Dimos, P. Chaudhari and J. Mannhart: "Superconducting transport properties of grain boundaries in $\mathrm{YBa}_{2} \mathrm{Cu}_{3} \mathrm{O}_{7}$ bicrystals," Phys. Rev. B 41 (1990) 4038-4049

9) Y. Iijima, N.Tanabe, O. Kohno and Y. Ikeno: "In-plane aligned $\mathrm{YBa}_{2} \mathrm{Cu}_{3} \mathrm{O}_{7-\mathrm{x}}$ thin films deposited on polycrystalline metallic substrates," Appl. Phys. Lett. 60 (1992) 769-771

10) A. Goyal, et al.: "High critical current density superconducting tapes by epitaxial deposition of $\mathrm{YBa}_{2} \mathrm{Cu}_{3} \mathrm{O}_{x}$ thick films on biaxially textured metals," Appl. Phys. Lett. 69 (1996) 1795-1797

11) Y. Shiohara, T. Taneda and M. Yoshizumi: "Overview of materials and power applications of coated conductors project," Jpn. J. Appl. Phys. 51 (2012) 010007

12) T. Katase, et al.: "Advantageous grain boundaries in iron pnictide superconductors," Nat. Commun. 2 (2011) 409

13) J.D. Weiss, et al.: "High intergrain critical current density in finegrain $\left(\mathrm{Ba}_{0.6} \mathrm{~K}_{0.4}\right) \mathrm{Fe}_{2} \mathrm{As}_{2}$ wires and bulks," Nat. Mater. 11 (2012) 682-685

14) Y. Ma, et al.: "Progress in wire fabrication of iron-based superconductors," Supercond. Sci. Technol. 25 (2012) 113001

15) Z. Gao, K. Togano, A. Matsumoto and H. Kumakura: "Achievement of practical level critical current densities in $\mathrm{Ba}_{1-x} \mathrm{~K}_{x} \mathrm{Fe}_{2} \mathrm{As}_{2} / \mathrm{Ag}$ tapes by conventional cold mechanical deformation," Sci. Rep. 4 (2014) 4065

16) K. Togano, Z. Gao, A. Matsumoto, A. Kikuchi and H. Kumakura: "Fabrication of $(\mathrm{Ba}, \mathrm{K}) \mathrm{Fe}_{2} \mathrm{As}_{2}$ tapes by ex situ PIT process using Ag-Sn alloy single sheath," Supercond. Sci. Technol. 30 (2017) 015012

17) H. Sato, H. Hiramatsu, T. Kamiya and H. Hosono: "Enhanced critical-current in P-doped $\mathrm{BaFe}_{2} \mathrm{As}_{2}$ thin films on metal substrates arising from poorly aligned grain boundaries," Sci. Rep. 6 (2016) 36828

18) H. Hiramatsu, H Sato, T Kamiya and H Hosono: " $\mathrm{BaFe}_{2}\left(\mathrm{As}_{1-x} \mathrm{P}_{x}\right)_{2}$ $(x=0.22=0.42)$ thin films grown on practical metal-tape substrates 
and their critical current densities," Supercond. Sci. Technol. 30 (2017) 044003

19) S.R. Foltyn, et al.: "Materials science challenges for hightemperature superconducting wire," Nat. Mater. 6 (2007) 631-642

20) J.L. MacManus-Driscoll, et al.: "Strongly enhanced current densities in superconducting coated conductors of $\mathrm{YBa}_{2} \mathrm{Cu}_{3} \mathrm{O}_{7-\mathrm{x}}$ +BaZrO 3 ," Nat. Mater. 3 (2004) 439-443

21) V. Selvamanickam, et al.: "Critical current density above $15 \mathrm{MAcm}^{-2}$ at $30 \mathrm{~K}, 3 \mathrm{~T}$ in $2.2 \mu \mathrm{m}$ thick heavily-doped $(\mathrm{Gd}, \mathrm{Y})$ $\mathrm{Ba}_{2} \mathrm{Cu}_{3} \mathrm{O}_{\mathrm{x}}$ superconductor tapes," Supercond. Sci. Technol. 28 (2015) 072002.

22) K. Matsumoto and P. Mele: "Artificial pinning center technology to enhance vortex pinning in YBCO coated conductors," Supercond. Sci. Technol. 23 (2010) 014001

23) J. Gutiérrez, et al.: "Strong isotropic flux pinning in $\mathrm{YBa}_{2} \mathrm{Cu}_{3} \mathrm{O}_{7-\mathrm{x}}$ $+\mathrm{BaZrO}_{3}$ films derived from chemical solutions," Nat. Mater. 6 (2007) 367-373

24) B. Maiorov, et al. "Synergetic combination of different types of defect to optimize pinning landscape using $\mathrm{BaZrO}_{3}$-doped $\mathrm{YBa}_{2} \mathrm{Cu}_{3} \mathrm{O}_{7}$," Nat. Mater. 8 (2009) 398

25) M. Miura et al.: "Upward shift of the vortex solid phase in hightemperature superconducting wires through high density nanoparticle addition," Sci. Rep. 6 (2016) 20436

26) M. Miura, et al.: "Tuning nanoparticle size for enhanced functionality in perovskite thin films deposited by metal organic deposition," NPG Asia Mater. 9 (2017) e447

27) S. Lee, et al.: "Template engineering of Co-doped $\mathrm{BaFe}_{2} \mathrm{As}_{2}$ single-crystal thin films," Nat. Mater. 9 (2010) 397-402

28) S. Lee, et al.: "Artificially engineered superlattices of pnictide superconductors," Nat. Mater. 12 (2013) 392

29) T. Ozaki, et al.: "A route for a strong increase of critical current in nanostrained iron-based superconductors," Nat. Commun. 7 (2016) 13036

30) M. Miura, et al.: "Anisotropy and superconducting properties of $\mathrm{BaFe}_{2}\left(\mathrm{As}_{1-x} \mathrm{P}_{x}\right)_{2}$ films with various phosphorus contents," Appl. Phys. Express 6 (2013) 093101

31) M. Miura, et al.: "Strongly enhanced flux pinning in one-step deposition of $\mathrm{BaFe}_{2}\left(\mathrm{As}_{0.66} \mathrm{P}_{0.33}\right)_{2}$ superconductor films with uniformly dispersed $\mathrm{BaZrO}_{3}$ nanoparticles," Nat. Commun. 4 (2013) 2499

32) E.H. Brandt: "Large range of validity of linear elasticity of the vortex lattice in high- $T_{\mathrm{c}}$, superconductors," Phys. Rev. Lett. 69 (1992) 1105-1108

33) A. Gurevich: "Pinning size effects in critical currents of superconducting films," Supercond. Sci. Technol. 20 (2007) S128S135

34) M. Miura, et. al.: "Enhancement of flux pinning in epitaxial TFAMOD TFA-MOD $\mathrm{Y}_{1-x} \mathrm{Sm}_{x} \mathrm{Ba}_{1.5} \mathrm{Cu}_{3} \mathrm{O}_{y}$ with nanoparticles coated conductors," Appl. Phys. Express 1 (2008) 051701

35) T.G. Holesinger, et al.: "Progress in nano-engineered microstructures for tunable high-current, high temperature superconducting wires,” Adv. Mater. Prog. Rep. 20 (2008) 391-407
36) M. Miura, et al.: "Dislocation density and critical current density of $\mathrm{Sm}_{1+\mathrm{x}} \mathrm{Ba}_{2-\mathrm{x}} \mathrm{Cu}_{3} \mathrm{O}_{y}$ films prepared by various fabrication processes,” Jpn. J. Appl. Phys. 45 (2006) L701-L704

37) M. Miura, et al.: unpublished (2017)

38) L.D. Cooley, P.J. Lee and D.C. Larbalestier: "Flux-pinning mechanism of proximity-coupled planar defects in conventional superconductors: evidence that magnetic pinning is the dominant pinning mechanism in niobium-titanium alloy," Phys. Rev. B 53 (1996) 6638-6652

39) C.G. Zhuang, et al.: "Significant improvements of the high-field properties of carbon-doped $\mathrm{MgB}_{2}$ films by hot-filament-assisted hybrid physical-chemical vapor deposition using methane as the doping source," Supercond. Sci. Technol. 21 (2008) 082002

40) A.E. Koshelev and A.B. Kolton: "Theory and simulations on strong pinning of vortex lines by nanoparticles," Phys. Rev. B 84 (2011) 104528

41) S. Eley, M. Miura, B. Maiorov and L. Civale: "Universal lower limit on vortex creep in superconductors," Nat. Mater. 16 (2017) 409-413

42) M. Miura, et al.: "Mixed pinning landscape in nanoparticleintroduced $\mathrm{YGdBa}_{2} \mathrm{Cu}_{3} \mathrm{O}_{y}$ films grown by metal organic deposition," Phys. Rev. B 83 (2011) 184519

43) P. Yuan, et al.: "Vortex pinning properties in Co-doped $\mathrm{BaFe}_{2} \mathrm{As}_{2}$ thin films with a high critical current density over $2 \mathrm{MAcm}^{-2}$ at 9 T," Supercond. Sci. Technol. 30 (2017) 025001

44) J. Lee, et al.: "High critical current density over $1 \mathrm{MAcm}^{-2}$ at $13 \mathrm{~T}$ in $\mathrm{BaZrO}_{3}$ incorporated $\mathrm{Ba}(\mathrm{Fe}, \mathrm{Co})_{2} \mathrm{As}_{2}$ thin films," Supercond. Sci. Technol. 30 (2017) 085006

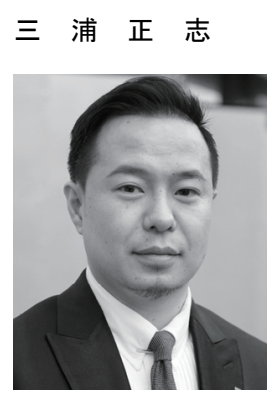

1980 年 5 月生。2005 年名古屋大学大学 院工学研究科博士前期課程修了。2006 年 日本学術振興会 DC 特別研究員 (名古屋大 学)。2007 年名古屋大学大学院工学研究 科博士後期課程短縮修了。2007 年 日本学 術振興会 PD 特別研究員 ((公財) 国際超電 導産業技術研究センター超電導工学研究 所）。2009 年米国ロスアラモス国立研究 所 Superconductivity Technology Center 客員 研究員。2010 年米国ロスアラモス国立研 究所 Director's Postdoctoral Fellow。2012 年 成蹊大学大学院 准教 授を経て、2017 年 成蹊大学大学院 理工学研究科 教授。2014 年 第 28 回独創性を拓く先端技術大賞 フジサンケイビジネスアイ 賞、2016 年 平成 28 年度全国発明表彰 21 世紀発明賞、2017 年 科学技術分野の文部科学大臣表彰 若手科学者賞を受賞。現在、 RE 系及び Fe 系超伝導線材の磁場応用に向けた磁束ピンニング機 構と超伝導特性に関する研究に従事。低温工学・超電導学会、応 用物理学会、日本金属学会会員。博士 (工学)。 